\title{
Can't buy mommy's love? Universal childcare and children's long-term cognitive development
}

\author{
Christina Felfe • Natalia Nollenberger • \\ Núria Rodríguez-Planas
}

Received: 8 August 2013 / Accepted: 2 August 2014

(C) Springer-Verlag Berlin Heidelberg 2014

\begin{abstract}
What happens to children's long-run cognitive development when introducing universal high-quality childcare for 3-year-olds mainly crowds out family care? To answer this question, we take advantage of a sizeable expansion of publicly subsidized full-time high-quality childcare for 3-year-olds in Spain in the early 1990s. Identification relies on variation in the initial speed of the expansion of childcare slots across states. Using a difference-in-difference approach, we find strong evidence for sizeable improvements in children's reading skills at age 15 ( 0.15 standard deviation) and weak evidence for a reduction in grade retentions during primary school (2.5 percentage points). The effects are driven by girls and disadvantaged children.
\end{abstract}

Keywords Universal high-quality childcare $\cdot$ Long-term consequences $\cdot$ Cognitive skills

JEL Classification $\mathrm{J} 13 \cdot \mathrm{I} 28$

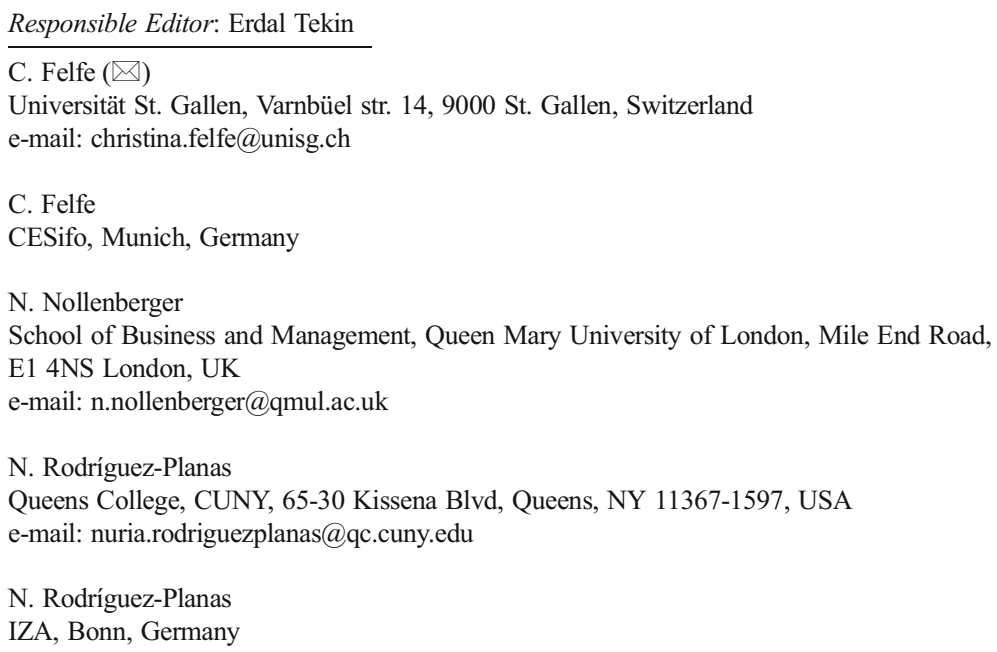




\section{Introduction}

Governments on both sides of the Atlantic are currently discussing rolling out public childcare. For instance, in his last presidential address, Barack Obama proposed "to make high-quality preschool available to every child in America" (Economist 2013). In Germany, the recently introduced legal right for parents to have a place in a public childcare center once their child is a year old represented one of the most contested issues ahead of the general election in 2013 (Economist 2013). Yet, what are the consequences of high-quality public childcare for children's development?

When judging the effects of publicly provided childcare on child outcomes, it is important to consider the quality of both the publicly provided care and the existing care. In addition, there are (at least) two further important dimensions to child outcomes in this literature: short- or medium-run versus long-run outcomes and cognitive versus non-cognitive outcomes. This paper aims to understand the effects of introducing high-quality public childcare on children's long-run cognitive development when it crowds out care provided by the nuclear family. More specifically, we use a natural experiment framework to analyze whether expanding high-quality public childcare for 3-year-olds influences children's cognitive performance by the end of mandatory schooling in a context in which the counterfactual care mode is family care. Analyzing the impact of a substitution between family care and public care on children's development is interesting from at least two points of view. First, it improves our understanding of the role of alternative care modes on skill acquisition early in life and thus contributes to the literature examining the determinants of children's human capital formation. Second, family care, particularly motherly care, is still perceived to be best for children in many countries. This perception is one, if not even the main, factor hampering the equality of men and women on the labor market. Thus, analyzing the role of public care in comparison to family care, which is mostly provided by the mother, might help to change role models and thus foment women's status in the labor market.

Our focus lies on an early 1990s reform in Spain, which led to a sizeable expansion of publicly subsidized full-time high-quality childcare for 3-year-olds. This reform implied universal access to high-quality public childcare for all 3-year-olds, independent of their family background. Following the reform, overall enrollment in public childcare among 3-year-olds increased from $8.5 \%$ in 1990 to $29.1 \%$ in 1993, $42.9 \%$ in 1997 , and $67.1 \%$ in 2002. Importantly, this reform had a modest effect on maternal employment, did not affect fertility, and did not lead to a crowding out of private childcare (see a significantly revised version of Nollenberger and Rodríguez-Planas 2011). Moreover, a crowding out of informal care was unlikely, given that most 3-yearolds whose mothers worked prior to the reform were already enrolled in either public or private childcare. As a result, our effects should be mainly interpreted as the effects of substituting family care by high-quality public care. In addition, the income effect - due to either a reduction in childcare costs (by crowding out private childcare) or an increase in maternal earnings (by increasing maternal employment) - is rather negligible. ${ }^{1}$

\footnotetext{
${ }^{1}$ In this aspect, our paper contrasts with that of Black et al. (2012) in which the authors are able to isolate the effects of childcare subsidies on both parental and student outcomes.
} 
The Spanish reform also included a federal provision of several quality aspects (such as curriculum, group size, and staff skill composition). While the quality improvements are applied to preschool in general (to childcare for 3-, 4-, and 5year-olds) and thus were not exclusive to the children who were directly affected by the expansion of public childcare at age 3, it is important to bear in mind that our findings have to be interpreted as the consequences of introducing regulated highquality care.

Although the reform was national, the responsibility for implementing its preschool component was transferred to the states. The timing of such implementation expanded over 10 years and varied considerably across states. We exploit the initial variation in the speed of the implementation of public childcare slots to isolate the impact of providing high-quality public care on children's educational achievements in the long run. Our main empirical strategy is thus a difference-in-difference (henceforth, DiD) design, which is structured as follows: we compare the educational outcomes of children (at age 15) who were 3 years old before and after the reform in states where public childcare expanded substantially (from a coverage rate of $9.9 \%$ in $1990 / 1991$ to $44.0 \%$ in $1993 / 1994$ and $57.1 \%$ in 1996/1997) and states with a less pronounced increase in public childcare (from a coverage rate of $7.4 \%$ in $1990 / 1991$ to $15.3 \%$ in $1993 / 1994$ and $29.4 \%$ in $1996 / 1997$ ) in the years immediately after the reform.

The data used in this study stem from the 2000, 2003, 2006, and 2009 Programme for International Student Assessment (PISA). Children from PISA 2000 and 2003 were born in 1984 and 1987, respectively, and hence, they were 7 and 4 years old when the reform was first implemented in 1991. Consequently, they were unaffected by the expansion of publicly subsidized childcare for 3-year-olds. Children from PISA 2006 and 2009 were born in 1990 and 1993, respectively, and thus they were affected by the expansion of childcare at age 3 .

We find that the introduction of universal high-quality public childcare for 3-yearolds led to a sizable increase in reading test scores. More specifically, we find improved reading test scores at age 15 by 0.15 standard deviations. Moreover, we find some weak evidence of the reduced likelihood of falling behind a grade. In particular, the prevalence of grade retention in primary school declined by 2.5 percentage points. Our results are robust to the use of alternative specifications and alternative identification strategies. In addition, placebo estimates pretending that the reform took place in the pre-reform period support the hypothesis that our findings are not spurious.

Subgroup analysis with respect to gender reveals that the achievement effects are mainly present among girls. This gender heterogeneity is in line with existing research reporting larger benefits of public childcare for girls than boys (Gathmann and Saß 2012; Havnes and Mogstad 2011). Subgroup analysis with respect to parental education also supports the findings from previous studies that public childcare is particularly beneficial for children from disadvantaged backgrounds (Datta Gupta and Simonsen 2010; Havnes and Mogstad 2011; Fitzpatrick 2008). Finally, subgroup analysis by PISA cohorts and thus by earlier and later periods after the reform reveals stronger consequences in terms of the development of children being 3 years old in the early years after the reform. 
Our paper builds on the existing research concerning the effects of public childcare on children's development. ${ }^{2}$ This research can be classified according to the type of care being crowded out by the expansion of public care: crowding out of paid (private) care, crowding out of targeted care, crowding out of informal care, or crowding out of family care. The seminal study by Baker et al. (2008) focuses on a setting in which public childcare replaced mainly private (paid) childcare arrangements. Exploiting the introduction of highly subsidized childcare in Québec, they find negative effects on children's short-run health and well-being. Cascio (2009) documents reductions in high school dropouts and institutionalization after the introduction of public childcare in the USA in the 1960s and 1970s. However, the positive effects are only found among whites but not among other groups of the population that are likely to enjoy targeted (and thus higher quality) care. Fitzpatrick (2008) and Havnes and Mogstad (2011) analyze the consequences of crowding out informal care (that is, nannies or childminders). Both studies document the positive effects of moving children from informal care to public care on children's educational outcomes. Havnes and Mogstad (2011) also report positive effects on children's labor force participation when they reach adulthood. Our study falls into the category of papers that focus on settings in which public childcare crowds out mainly family care. Most of the existing studies analyzing the consequences of public childcare crowding out family care focus on short-run effects on children's outcomes (Datta Gupta and Simonsen 2010; Felfe and Lalive 2012). The only exception is Drange et al. (2012) who analyze the consequences of a reform in Norway in 1997 that lowered the mandatory school starting age from 7 to 6 in terms of children's cognitive outcomes at the end of mandatory schooling. In contrast to our paper, their paper finds no significant effects, although the following differences between the two studies might explain the conflicting evidence. First, the two studies analyze childcare targeted to different age groups, with our study focusing on childcare for 3-year-olds, whereas their study focuses on childcare for 6-year-olds. A program that (like ours) focuses on learning through play is likely to matter more for younger children. Second, in contrast to Spain, access to childcare in Norway was already substantial prior to the reform; in other words, the two studies analyze the consequences of expanding public childcare at different levels of supply. At a higher level of initial supply, such as in Norway, parents might have sorted relatively efficiently into the existing programs, so that children who are not in such programs might in fact opt out, partly because they will benefit little from them. Finally, the two studies consider very different geographical and thus also potentially cultural areas, one in the most northern part of Europe and the other in the most southern part.

The reminder of the paper is organized as follows. The next section provides an overview of the institutional background. Sections 3 and 4 present the empirical

\footnotetext{
${ }^{2}$ Please refer to Appendix Table A.1 for an overview of the research on the impact of public childcare on children's development. In addition, several recent studies evaluate the other side of the coin: the impact of maternal care on children's development. Exploiting parental leave expansions, most studies do not find any significant effect on children's long-run development (Baker and Milligan 2011; Dustmann and Schöenberg 2012; Liu and Oskar 2010; Rasmussen 2010). The exception is Carneiro et al. (2011) who find improvements in children's long-run educational outcomes following a parental leave expansion in Norway. Likewise, a recent paper by Bettinger et al. (2013) exploits the introduction of an allowance paid to parents who do not utilize public care as an exogenous shock to maternal time devoted to their children in Norway. They also find positive effects on elderly siblings' long-run educational outcomes.
} 
strategy and the data. Sections 5, 6, and 7 present the main results, the sensitivity analysis, and the heterogeneity analysis, respectively, before Section 8 concludes.

\section{Background information}

\subsection{Institutional background prior to the reform}

Female labor force participation rates in Spain are among the lowest in the OECD. In 1990, before the reform under analysis came into force, the Spanish female labor force participation rate was $43 \%$. In addition, Spanish mothers experienced a large drop in post-birth employment, as explained in Gutierrez-Domenech (2005): first-time mothers' employment drops from $70 \% 2$ years prior to having a child to $34 \% 10$ years afterwards. The reasons for such a scenario are manifold. In the late 1980s and early 1990s, Spain was not a family-friendly country for working parents (and especially working mothers), as reflected by its low levels of social assistance to families (Adserà 2004), one of the shortest maternity leaves in Europe with 14 to 16 weeks of paid leave (Gutierrez-Domenech 2005), an extremely low incidence of part-time work with only $8 \%$ of all jobs in 1990 (Fernández-Kranz and Rodríguez-Planas 2011), as well as a rigid labor market with many jobs in the service sector having a split shift from 9 a.m. to 2 p.m. and from 5 to 8 p.m. (Amuedo-Dorantes and de la Rica 2009). Moreover, Spain was a traditional country with low male participation in household production (Bettio and Villa 1998).

While mandatory schooling in Spain began at age 6, preschool for 4- and 5-yearolds was also offered at the premises of primary schools from 9 a.m. to 5 p.m. (regardless of school ownership status). Once a primary school offered places for 4year-olds, parents who wished to enroll their children in that particular school did so when the child turned 4 years old, as the chance of being accepted by the school might considerably decrease a year later (as priority for enrollment of 5- and 6-year-olds was given to those children already enrolled in that particular school). Consequently, enrollment rates for 4- and 5-year-olds in the late 1980s were 94 and $100 \%$, respectively.

Primary and secondary schooling was either public or private. ${ }^{3}$ Public schools were free of charge, except for school lunch, which cost about 100 euros per child per month. Private school costs were higher-between 250 and 350 euros per child per month (including lunch).

At the beginning of the 1990s, childcare for children 0 to 3 years old was rather scarce, predominantly private, and also relatively expensive (on average, costing between 300 and 400 euros per child per month, including lunch). Family day care, whereby a reduced number of children is under the care of a certified person in her house, was practically non-existent. In Spain, children under 4 years old were thus either in formal (public or private) childcare - which was true for $28.7 \%$ of all 3-yearolds - or with their mother or grandmother. Unfortunately, information on grandmother care is unavailable; in other words, we cannot distinguish between care provided by the

\footnotetext{
${ }_{3}^{3}$ About one third of children in primary school in Spain are enrolled in private schools. In this paper, private schools refer to escuelas concertadas for which the government subsidizes the staff costs (including teachers).
} 
mother and care provided by the grandmother and thus analyze the substitution of care provided by the nuclear family.

\subsection{The reform}

In 1990, Spain underwent a major national education reform (named Ley Orgánica de Ordenación General del Sistema Educativo), which affected preschool, primary school, and high school. The focus of our study is on the preschool component of this reform, which consisted of regulating the supply and quality of preschool. Its implementation began in the 1991/1992 school year. The primary and secondary school component of the reform increased mandatory schooling by 2 years (from age 14 to age 16) starting from the 1996/1997 school year. In addition, it established that primary school would end at age 12 (instead of age 14). Our analysis isolates the effect of the preschool component by focusing on children born between 1984 and 1993 who were all affected by the primary and secondary school component but not necessarily by the preschool component. ${ }^{4}$

The LOGSE divided preschool into two levels: the first level included children up to 3 years old, while the second level included children 3 to 5 years old. While not introducing mandatory attendance, the government began regulating the supply of slots for 3-year-olds. Prior to the LOGSE, free universal preschool education had only been offered to children aged 4 to 5 years old. After the LOGSE, preschool slots for 3-yearolds were offered within the premises of primary schools and were run by the same team of teachers. This implied that childcare for 3-year-olds was free of charge, operated on a full-day basis during the five working days, and followed a homogeneous and well-designed program.

With the introduction of the LOGSE, schools had to accept children in September of the year in which the child turned 3 whenever parents asked for admission, if places were available. Importantly, there were no eligibility criteria, but available preschool places were allocated among those who had requested admission by lottery (regardless of parents' employment, marital status, or income). In other words, acceptance did not depend on children's family background, thus implying that the reform made preschool de facto universal. As previously explained, although enrollment was not mandatory, it was necessary to ensure a place in the parents' preferred school choice. Consequently, childcare enrollment among 3-year-old children went from meager to universal in a matter of a decade, with most of the increase occurring in public schools. ${ }^{5}$ Between the academic years of 1990/1991 and 2002/2003, the number of 3-year-old children enrolled in public preschool centers increased extraordinarily from 33,128 to 238,709. This represented an increase in public enrollment of 3-year-olds by more than 58.6 percentage points, from 8.5 to $67.1 \%$. Federal funding for preschool and primary education increased from an average expenditure of 1,769 euros per child in 1990/1991 to 2,405 euros in 1996/1997 (both measured in 1997 constant euros), implying a $35.9 \%$ increase in education expenditure per child. ${ }^{6}$

\footnotetext{
${ }^{4}$ See Felgueroso et al. (2014) for an analysis of the effects of the primary and secondary school component of the reform on high school dropout rates.

${ }^{5}$ Unfortunately, we only have information on enrollment rates and not on actual supply rates. In the context of rationed supply, enrollment rates should, however, resemble coverage rates quite closely.

${ }^{6}$ Unfortunately, data disaggregated at the preschool level or at a lower regional level is not available.
} 
Apart from regulating the supply of public childcare, LOGSE also provided federal provisions for the first time in Spain regarding educational content, group size, and staff skill composition for children 3 to 5 years old, regardless of ownership status. Psychoeducational theories such as constructivism (put forward by Jean Piaget and Lev Vygotski) and progressive education (based on Célestin Freinet and Ovide Decroly) served as guidelines for the design of the curriculum. There was a strong emphasis on play-based education, group play, and learning through experiencing the environment. ${ }^{7}$ The particular objectives of preschool education focused on (1) personal development, in which the child masters its own body and understands its own movement possibilities; (2) emotional development, in which the child interacts with others in a variety of context and communication modes; (3) social development, in which the child forms good relationships with adults and peers and understands that people have different needs, views, cultures, and beliefs; and (4) personal autonomy in the child's usual activities (LOGSE, Ley Organica 1, 1990). Notice that the targeted competencies - emotional and social competencies - constitute the basis for children's literacy development (Lenneberg 1964). In addition, the first 3 years of life correspond to the critical phase of language acquisition, while analytical and math skills are developed slightly later at age 4-6 (Montessori 1963). Thus, we can expect that children mostly benefit from high-quality childcare at age 3 in terms of language skills.

In addition, the LOGSE established the maximum number of students per class to be 20 for 3-year-olds and 25 for 4- and 5-year-olds. It is important to point out that classes are grouped based on the year in which children were born and thus are not mixed in ages. Finally, the LOGSE required preschool teachers to have a college degree in pedagogy, which was previously only enforced for teachers of 4- and 5-year-olds. Recent findings by Bauchmüller et al. (2014), highlighting that a lower staff/child-ratio and a higher share of staff with a pedagogic education lead to significant improvements in children's language test results at age 15/16, might further prompt us to expect a positive impact of the LOGSE on children's language development.

Despite being a national law and financed nationwide, the responsibility for implementing the expansion of public preschool slots was transferred to the states. The timing of this implementation expanded over 10 years and varied considerably across states. Implementation lags arose largely due to a scarcity of qualified teachers and constraints on classroom space in existing primary schools (El País 2005). In fact, in 1990, the number of children per classroom (in public and private childcare centers for children age 0 to 5 years old) was 24.1 among states that expanded childcare faster versus 27.2 among those that did so more slowly. In addition, an initially higher level of private childcare facilities in fast-expanding states in comparison to slower-expanding states might have provided the necessary know-how to implement childcare facilities at a faster speed (see Section 3 for more details).

Our empirical strategy exploits the differences in the initial speed of implementation across states, which is likely to occur due to a slackening of financial constraints. It is important to bear in mind that the implementation of new slots in public childcare was largely paid by the federal government and thus would have been unlikely to occur (at the same speed) in the absence of the reform. This is further discussed in the next section.

\footnotetext{
${ }^{7}$ While the pedagogical movements behind the LOGSE are close to those in Scandinavian countries, they have been viewed as an alternative to the test-oriented instruction legislated by the No Child Left Behind educational funding act in the USA or the reception class in the UK.
} 


\section{Empirical specification}

Our identification strategy relies on the variation in the initial speed of implementing the preschool component of the LOGSE across states in Spain in the early 1990s. To be more precise, we compare the cognitive development at age 15 of children who were 3 years old before and after the reform in states where childcare significantly expanded (the high-intensity group) and in states where the increment in childcare coverage was less pronounced immediately after the reform (the low-intensity group). To determine the cut-off needed to define which states belong to the low- and high-intensity group, we follow Havnes and Mogstad (2011) and order states according to their percentage point increase in the public childcare enrollment of 3-year-olds in the years immediately after the reform, namely, between 1990 and 1993 (see Table 1). We subsequently separate the sample at the median. Those states that experienced an increase in public childcare enrollment above the median belong to our high-intensity group, whereas those with an increase under the median belong to our low-intensity group. Robustness checks using alternative cut-offs are shown in Section 5.

Figure 1a displays the average increase in public childcare enrollment for 3-yearolds for the high-intensity and low-intensity groups from 1987/1988 to 2002/2003. Prior to the reform, the difference in available slots in public childcare between lowand high-intensity states was relatively small: in 1990/1991, the enrollment rate of publicly available preschool places for 3-year-olds amounted to $9.9 \%$ in the highintensity group and $7.4 \%$ in the low-intensity group. Nonetheless, families living in high-intensity states experienced a much stronger initial increase in preschool places than those living in low-intensity states. For instance, among states in the high-intensity group, the public enrollment rate for 3-year-olds rose from $9.9 \%$ in 1990/1991 to

Table 1 Public childcare increase 1990-1993 (percentage points)

\begin{tabular}{llr}
\hline Treatment states & Galicia & 48.24 \\
& Cataluña & 42.96 \\
& Asturias & 32.93 \\
& Rioja & 29.67 \\
& Castilla y León & 29.11 \\
Cantabria & Madrid & 25.60 \\
Control states & Castilla-La Mancha & 24.90 \\
& & 23.25 \\
& Extremadura & 21.06 \\
& Aragón & 19.93 \\
& Baleares & 14.59 \\
& Valencia & 7.69 \\
& Andalucía & 5.63 \\
& Murcia & 4.51 \\
& Canarias & 4.15 \\
\hline
\end{tabular}

Source: Elaborated by authors based on educational statistics from the Spanish Ministry of Education, Culture and Sports 

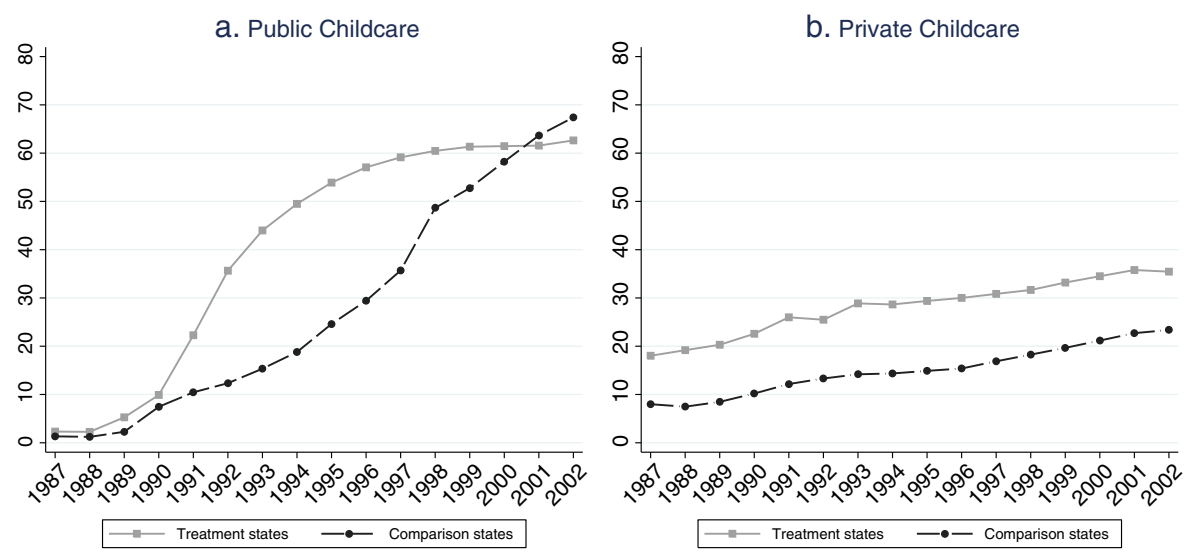

Fig. 1 Enrollment rates in childcare among 3-year-olds. Displayed numbers are weighted averages of enrollment rates for the treatment and control states. Weights reflect the population of each state (CCAA)

$44.0 \%$ in $1993 / 1994$, and $57.1 \%$ in $1996 / 1997$. In comparison, the public enrollment rate for 3-year-olds in the low-intensity group increased from 7.4 to $15.3 \%$ in $1993 / 1994$ and $29.4 \%$ in 1996/997. Figure 1a also shows that while there are dramatic differences in the initial expansion of public childcare, the low-intensity states fully catch up within a decade. Moreover, Fig. $1 \mathrm{~b}$ provides evidence that trends in private childcare are remarkably similar across the two groups, in contrast with the observed differences in public childcare. Thus, our study compares states that differ distinctly in terms of initial changes in public childcare coverage. The absence of any long-run difference in public childcare supply or trends in private childcare provides reason to believe that there is no differential long-run trend in the demand for childcare.

Our research design corresponds to a DiD method with the distinction that we do not evaluate a move from no coverage to full coverage but rather a high-intensity expansion versus a low-intensity expansion. In other words, our study allows for policy recommendations regarding a high-intensity expansion of high-quality public childcare versus a lowintensity expansion (and thus recommendations for changes at the intensive margin) but not regarding the introduction of high-quality public childcare (and thus the extensive margin).

Our basic DiD model, estimated by ordinary least squares (OLS), clustering standard errors at the state level and using the sample of children from PISA 2000, 2003, 2006 and 2009, is as follows: ${ }^{8}$

$$
Y_{i j t}=\beta+\gamma_{1} \text { Treat }_{i}+\gamma_{2} \text { Post }_{t}+\theta\left(\text { Treat }_{i} \times \text { Post }_{t}\right)+X_{i} \beta+Z_{j} \delta+\text { Cohort }_{t} \pi+\varepsilon_{i j t}
$$

where $Y_{i j t}$ measures the educational outcome a child $i$ achieves at age 15 (measured in year $t$, which corresponds to 2000,2003, 2006, or 2009, depending on the birth cohort of child $i-1984,1987,1990$, or 1993, respectively) living in state $j$ (which is one of the 16 states in Spain). Treat ${ }_{i}$ is a binary variable indicating whether or not child $i$ lives in one of the fast-implementing states. Post $t_{t}$ is a dummy equal to 1 if the child turned 3 years old after the reform took place in 1991. Children from PISA 2006 and 2009 were born in 1990 and 1993, respectively, and thus they were fully affected by the preschool

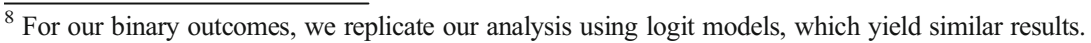


component of the LOGSE at age 3 if they lived in a state that rapidly expanded the supply of public childcare slots. Children from PISA 2000 and 2003 were born in 1984 and 1987, respectively. They were 7 and 4 years old when the LOGSE was first implemented, and thus they were unaffected by the expansion of publicly subsidized childcare. Therefore, Post $t_{t}$ takes on the value 1 for children belonging to the PISA cohorts 2006 and 2009, and zero for children belonging to the PISA cohorts 2000 and 2003. To allow for any underlying trend in the PISA test scores, we control for a set of cohort fixed effects (in other words, a set of dummies for the PISA cohort 2000, 2003, 2006, and 2009). ${ }^{9,10}$ The vector $X_{i}$ includes only time-invariant individual features that are expected to be correlated with educational achievement: gender and immigrant status. Since all additional socio-demographic characteristics that we observe at age 15 are time variant and thus potentially endogenous to our treatment, we decided not to include them in our main specification. However, our results are robust to sensitivity analysis, where we sequentially add these additional variables to Eq. 1, as shown in Appendix Table A.2. Finally, the vector $Z_{j}$ includes pre-reform state-specific features such as gross domestic product (GDP) per capita, unemployment rate, female employment rate, average educational level, and population density (measured as the average for the years 1987 to 1990). Controlling for such prereform-specific features shall account for the fact that some states are better equipped to expand childcare rapidly than others. In a separate specification, we allow for pre-reform heterogeneity within the group of treatment states by including state-specific fixed effects instead. As the coefficients vary little across these two specifications, we use the former as our main specification.

The coefficient $\theta$ belonging to the interaction term between the Treat ${ }_{i}$ dummy and the Post ${ }_{t}$ dummy measures the average effect of the increase in high-quality childcare slots for 3-year-olds in high-intensity states versus the increase in low-intensity states. For this estimate to be causal, the assumption of common trends needs to be fulfilled. In other words, in the absence of the reform, the outcomes for treated and comparison children should have evolved in parallel. Is this assumption credible or are there reasons to believe that there are further differences between high- and low-intensity states that could have sent children on different outcome paths in the absence of the reform?

By choosing the initial years after the reform, we aim at capturing variation in the speed of the expansion in high-quality public childcare due to a slackening of initial constraints and not due to differences in underlying preferences or demand. In other words, we believe that an expansion of public childcare of comparable magnitude would have been unlikely in any Spanish state without the federal subsidies provided due to the LOGSE, at least in the short run. Unfortunately, we lack a longer time series for the outcome variables to provide some evidence for parallel trends prior to the reform. Nonetheless, given two data points prior to treatment, we can estimate a placebo test assuming that the reform would have taken place in the late 1980s and thus affected the PISA 2003 cohort, yet not the PISA 2000 cohort (see Section 6 for

\footnotetext{
${ }^{9}$ Due to perfect collinearity between the constant and the Post ${ }_{t}$ dummy on the one hand and the PISA cohorts on the other hand, we omit two cohort dummies (2000 and 2009). Alternatively, we could omit the Post $t_{t}$ dummy and include dummies for both "post reform" cohorts (see Section 7).

${ }^{10}$ While we have administrative data on preschool enrollment at the lower level, we lack that information in PISA (in fact, gaining access to PISA data disaggregated at the state level is already quite hard). As such, our analysis relies on variation between states but ignores potential variation within states.
} 
results on this placebo estimation). In addition, we discuss supplementary evidence for the assumption of common trends.

Why were some states better equipped to implement the reform immediately, while others could do so only with a certain time lag? As discussed in Section 2, a lack of knowhow due to a lower level of private childcare, the scarcity of qualified teachers, and classroom space represented important barriers for a fast expansion. Nonetheless, while there were initial differences regarding such barriers across states, Fig. 2 shows that there was no differential improvement in available proxies for these barriers (such as the children/ staff ratio in public and private primary schools) after the implementation of the reform.

In addition, Fig. 3 presents an overview of the trends in several socio-economic features in low- and high-intensity states. There are important initial differences between the two groups (also shown in Table 2): high-intensity states appear to be located in the north, are less economically troubled, their population is more educated and slightly older, and they are more densely populated. Nevertheless, what is crucial for a DiD analysis is that the trends would have developed in parallel in the absence of the reform. A first inspection of Fig. 3 does not give reason to suspect different trends prior to the reform. In addition, Appendix Table A.3 tests for differential trends in statespecific features and thus for any potentially confounding developments in states expanding their public childcare at low versus high intensity. Indeed, we observe differential trends in some socio-economic features, namely, in GDP per capita, high school dropouts, and average years of education. However, there is no clear pattern that high-intensity states would develop systematically better or worse and, thus, that our estimates are systematically under- or overestimated. Since time-varying state-specific features are potentially endogenous to the reform, we decided not to include them in our main specification (where we only control for pre-treatment state-specific features). Nevertheless, the results of the sensitivity analysis, including relevant time-varying state-specific features, are shown in Appendix Table A.2 column 2.

The DiD approach only allows for statements related to the full expansion initiated by the LOGSE. An alternative approach is to exploit the regional and time variations in the number of public preschools slots for 3-year-olds, thus using a continuous measure

a. Students/Teachers - Public Centers

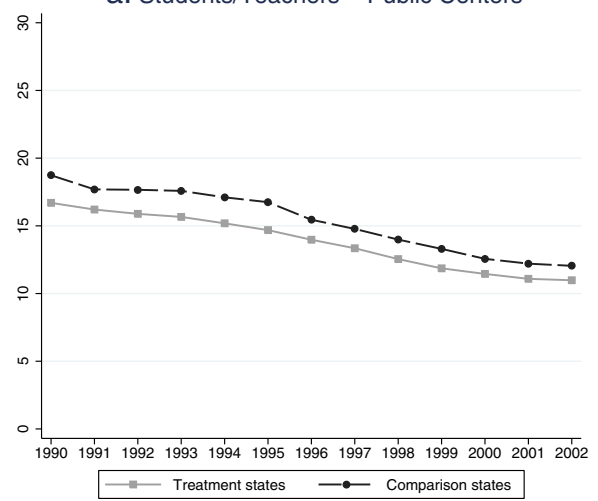

b. Students/Teachers - Private Centers

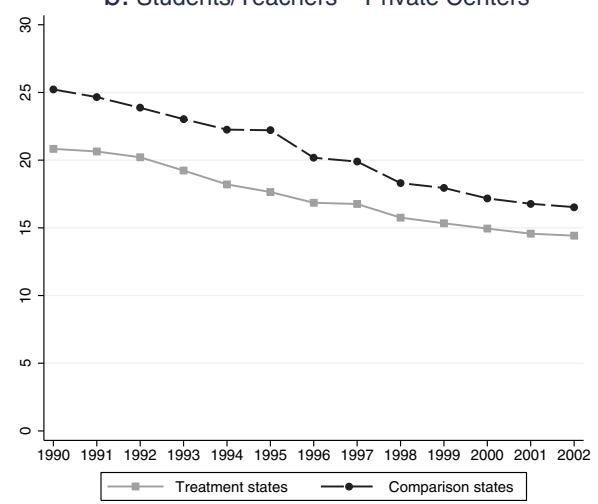

Fig. 2 Trends in primary school student/teacher ratios between 1990 and 2002. These are elaborated by the authors using data from the Ministry of Education (www.educacion.gob.es). We sum the total children enrolled in treatment and control states, respectively, and then divide it by the total number of teachers in each group of states (it is equivalent to do a weighted average across states within each group) 

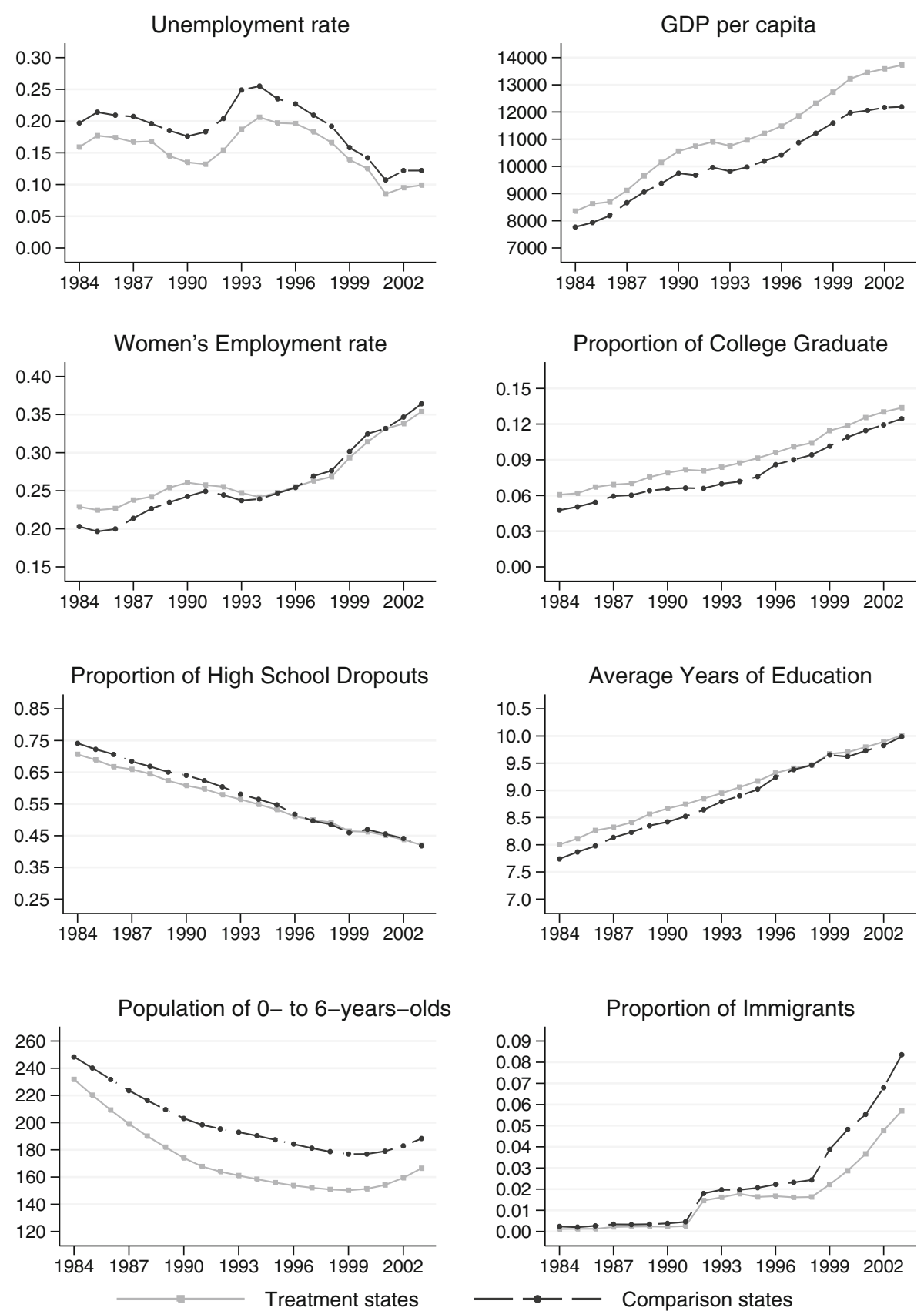

Fig. 3 Trends in further socio-economic state features 1984-2003. These are elaborated by the authors. Unemployment rate, women's employment rate, proportion of college graduate, proportion of high school drop outs, average years of education, and proportion of immigrants are calculated based on Spanish LFS microdata (we consider individuals 16 years old onwards). GDP per capita and population of population of 0to 6-years-olds are calculated based on regional data from the Spanish Statistics Institute (www.ine.es). GDP is expressed in constant euros of 1995. Average population of 0- to 6-years-olds is expressed in thousands 
Table 2 Pre-reform descriptive statistics - control variables

\begin{tabular}{llllllll}
\hline & Treatment states & Control states & Differences & \\
\hline A Individual characteristics & & & & & & \\
$\quad$ Gender (male=1) & 0.485 & {$[0.500]$} & 0.494 & {$[0.500]$} & -0.009 & $(0.015)$ \\
$\quad$ Born in Spain & 0.996 & {$[0.062]$} & 0.997 & {$[0.053]$} & -0.001 & $(0.002)$ \\
B Regional characteristics & & & & & & \\
GDP (euros/capita) & 10,687 & {$[2,136]$} & 8,543 & {$[1,481]$} & $2,144^{*}$ & $(1,085)$ \\
Unemployment rate-males & 0.114 & {$[0.024]$} & 0.186 & {$[0.068]$} & $-0.072^{* *}$ & $(0.032)$ \\
Unemployment rate-females & 0.227 & {$[0.054]$} & 0.315 & {$[0.070]$} & $-0.088^{* *}$ & $(0.039)$ \\
Employment rate-females & 0.262 & {$[0.044]$} & 0.209 & {$[0.043]$} & $0.053^{*}$ & $(0.026)$ \\
Years of education-males & 8.919 & {$[0.573]$} & 8.456 & {$[0.233]$} & $0.464^{*}$ & $(0.252)$ \\
Years of education-females & 8.400 & {$[0.419]$} & 8.028 & {$[0.227]$} & $0.371^{*}$ & $(0.185)$ \\
Total population (in millions) & 4.022 & {$[1.816]$} & 4.368 & {$[2.502]$} & -0.346 & $(1.502)$ \\
0- to 6-years-old (percentage) & 0.076 & {$[0.007]$} & 0.094 & {$[0.011]$} & $-0.018^{* * *}$ & $(0.005)$ \\
Population density (inhabitants per $\left.\mathrm{km}^{2}\right)$ & 247.637 & {$[228.343]$} & 103.633 & {$[51.718]$} & 144.004 & $(113.176)$ \\
Sample sizes & 6,846 & & 4,650 & & &
\end{tabular}

Notes: The pre-reform period includes data from 2000 and 2003 PISA. The displayed sample sizes correspond to PISA datasets and are not weighted. The table displays means and standard deviations shown in brackets. The asterisks indicate statistically significant differences between treatment and control states: *significant at $10 \%$ level; **significant at $5 \%$ level; ***significant at $1 \%$ level. Standard errors in parenthesis are clustered at the state level. Regional characteristics are calculated by the authors based on Spanish LFS microdata (unemployment, education, female employment rate) and on data at regional level available in www.ine.es (GDP, population, 0- to 6-years-old, population density)

of the expansion in public childcare. As numbers of slots available in public preschool are not available for detailed age groups, we employ a proxy: the number of public preschool units available for 3 - to 5 -year-olds. ${ }^{11}$ Figure 4 displays the overall increase in available slots for 3- to 5-year-olds from 1987/1988 to 2002/2003. To estimate this relationship, we follow Berlinski and Galiani (2007) and estimate the effect of offering one additional seat in public childcare, estimating the following equation by OLS:

$$
Y_{i j(t+12)}=\theta \text { Seats }_{j t}+\sum_{s=1987}^{1993} \alpha_{s} l(s=t)+X_{i} \beta+Z_{j} \delta+\varepsilon_{i j(t+12)}
$$

where $t=1987,1990,1993$, and 1996 , and $Y_{i j}(t+12)$ is a measure of the educational outcome that child $i$ achieves at age 15 measured in year $(t+12)$, which corresponds to $2000,2003,2006$, or 2009, depending on the birth cohort of child $i-1984,1987,1990$, or 1993, respectively, living in state $j$ (which is one of the 16 states in Spain). Seats $j t$ is the number of public preschool seats per 100 for children aged 3 to 5 years old in state $j$ in the year $t$. The vector $X_{i}$ includes time-invariant individual characteristics (gender and immigration status). As in the baseline specification, we include state $\left(Z_{j}\right)$ and cohort fixed effects $\left(\sum_{s=1987}^{1993} \alpha_{s} l(s=t)\right)$. This specification has the advantage that it

\footnotetext{
${ }^{11}$ Following Berlinski and Galiani (2007), we estimate the proportion of public preschool seats offered in each state as the number of public preschool units available for 3- to 5-year-olds in each region times the average size of the classroom divided by the population of 3- to 5-year-olds in each state.
} 


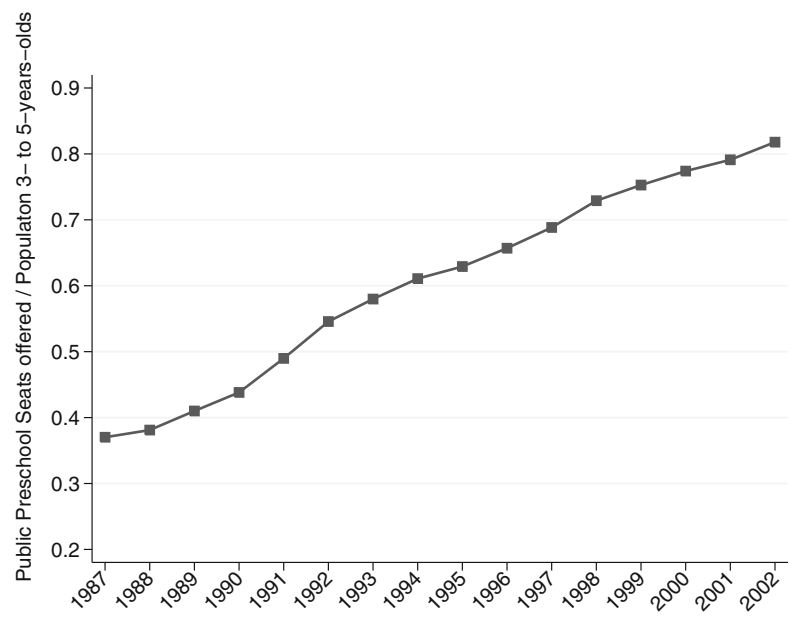

Fig. 4 Available slots in public childcare among 3- to 5-year-olds. These are elaborated by the authors based on Educational Statistics from the Spanish Ministry of Education, Culture and Sports. The proportion of public preschool seats offered in each state was estimated as the number of public preschool units available for 3- to 5-year-olds in each region times the average size of the classroom divided by the population of 3- to 5-year-olds in each state

does not rely on the definition of treatment status. However, it assumes a constant effect of offering one further childcare slot across the whole offer distribution. Thus, offering the 11th seat for every hundred children is assumed to have the same effect as the 91st seat per hundred children.

Before turning to a description of the data, we would like to mention that we also analyze underlying mechanisms of our effects. For this purpose, we repeat the baseline DiD estimation but employ an alternative set of outcome variables, namely, maternal employment and enrollment in public and private childcare. As we do not observe whether a particular individual attended childcare at age 3, the latter two outcomes are measured at the state level. ${ }^{12}$

\section{Data}

We use data from three different sources: (1) data from PISA, an internationally standardized assessment jointly developed by participating economies and administered to 15year-olds in schools; (2) administrative data from the Spanish Ministry of Education, Culture and Sports; and (3) survey data from the Spanish Labor Force Survey (LFS). Every 3 years (beginning in 2000 in Spain), PISA tests whether students near the end of compulsory education have acquired the knowledge and skills essential for successful participation in the labor market. It administers tests in mathematics, reading, and science

\footnotetext{
$\overline{12}$ To account for the fact that there is a time- and state-varying trend in maternal employment that is positively correlated with the implementation of the reform but negatively correlated with maternal employment (or vice versa) - as shown by Nollenberger and Rodríguez-Planas (2011) — we add state-specific trends when the LHS variable is maternal employment. We abstain from doing so in our baseline estimates, as we only possess of PISA data at 4 points in time (every third year and not on an annual basis as it is the case for maternal employment data). Nevertheless, results for child outcomes including state-specific time trends are comparable in magnitude but less precise and are available upon request.
} 
to assess whether students can analyze, reason, and communicate effectively. Background questionnaires are completed by students and school principals, which help to provide detailed information on children, family, and school characteristics. Our analysis focuses on reading and mathematics as performance in these two domains are fully comparable across PISA cycles from 2000 onwards. Questions entering the scientific scores are not comparable before and after 2006 and thus are not included in our analysis (OECD 2006). The PISA sample is stratified at two stages: first, schools are randomly selected; and second, students at each school are randomly assigned to carry out the test in all three subjects. Participation in PISA is voluntary for schools and students, although a minimum participation rate of $65 \%$ (80\%) of schools (students) from the original sample is required for a country to be included in the international database. We check the robustness of our results to this double stratification sampling design by re-estimating the effects of the reform using Fay's balanced repeated replicated (BRR) methodology in Section 6. The test scores are standardized, implying that the estimated coefficient represents the percentage increase (or decrease) in standard deviations (henceforth SD). We also estimate the effect of the reform on two additional variables that are only available in the 2003 and 2009 PISA waves: falling behind a grade during primary school or secondary school. Unfortunately, PISA does not provide information on preschool attendance at specific ages and thus, similar to related studies in this field (Baker et al. 2008; Fitzpatrick 2008; Havnes and Mogstad 2011), our estimates are intention-to-treat (ITT) estimates only.

Administrative data include enrollment rates by age, state and type of school (public or private), as well as the number of preschool units (classrooms) by state, and type of school from the 1986/1987 school year onwards. Enrollment rates from the 1992/1993 school year onwards are available from the web page of the Ministry of Education, Culture and Sports. ${ }^{13}$ Data before 1992/1993 were taken from the Education Statistics yearbooks published by the Ministry of Education, Culture and Sports. ${ }^{14}$ The number of preschool units (classrooms) by state and type of school is also available from the web page of the Ministry from the 1986/1987 school year onwards; however, this information is not available by age. As explained in Section 3 (see footnote 11), we use the total number of preschool units to estimate a measure of the proportion of total preschool slots offered (to children from 3 to 5 years old).

We obtain information on maternal employment from 1987 to 1997 from the Spanish LFS, a quarterly cross-sectional dataset that gathers information on socio-demographic characteristics (such as, age, years of education, marital status, and state of residence), employment, and fertility (number of children living in the household and their birth year). ${ }^{15}$

We exclude immigrant children who arrived to Spain after their third birthday, as well as children residing in the Basque Country, Navarra, and Ceuta and Melilla. The reason

\footnotetext{
$\overline{13}$ See http://www.mecd.gob.es/servicios-al-ciudadano-mecd/estadisticas/educacion/no-universitaria/ alumnado/matriculado/series.html.

${ }^{14}$ As the Ministry did not publish the enrollment rates at state level in the yearbooks, they were calculated by the authors as the ratio between the number of children enrolled in public and private schools (available at state level in the Education Statistics yearbooks) and the population of the corresponding age group and state from the Spanish Statistics Institute. (http://www.ine.es/jaxi/menu.do?type=pcaxis\&path=/t20/p263/pob_91/\&file= pcaxis). We check the consistency of our calculations comparing overlapping data for the school years 1992/1993 and 1993/1994.

${ }^{15}$ Again, we do not observe children's day care enrollment, thus precluding us from analyzing a "first-stage" model, as in Cascio (2009) and Berlinski and Galiani (2007) with a dummy for public day care enrollment of the mother's youngest child as dependent variable.
} 
Table 3 Descriptive statistics — outcome variables

\begin{tabular}{|c|c|c|c|c|c|c|}
\hline & \multicolumn{2}{|c|}{ Treatment states } & \multicolumn{2}{|c|}{ Control states } & \multicolumn{2}{|l|}{ Differences } \\
\hline \multicolumn{7}{|l|}{ A Pre-reform } \\
\hline Standardized reading scores & 0.102 & {$[0.975]$} & -0.139 & [1.050] & $0.241 * * *$ & $(0.069)$ \\
\hline Standardized math scores & -0.055 & [1.005] & -0.38 & [0.996] & $0.325^{* * *}$ & $(0.068)$ \\
\hline Falling behind in primary school & 0.053 & {$[0.224]$} & 0.063 & {$[0.242]$} & -0.010 & $(0.015)$ \\
\hline Falling behind in secondary school & 0.230 & {$[0.421]$} & 0.29 & {$[0.453]$} & -0.059 & $(0.065)$ \\
\hline Sample sizes & \multicolumn{2}{|c|}{$6,846(4,128)$} & \multicolumn{2}{|c|}{$4,650(2,195)$} & & \\
\hline \multicolumn{7}{|l|}{ B Post-reform } \\
\hline Standardized reading scores & 0.012 & {$[0.967]$} & -0.377 & [1.020] & $0.389 * * *$ & $(0.057)$ \\
\hline Standardized math scores & 0.017 & {$[0.972]$} & -0.36 & {$[1.004]$} & $0.376^{* * *}$ & $(0.072)$ \\
\hline Falling behind in primary school & 0.092 & {$[0.290]$} & 0.128 & [0.334] & -0.036 & $(0.023)$ \\
\hline Falling behind in secondary school & 0.257 & {$[0.437]$} & 0.346 & {$[0.476]$} & $-0.089 * *$ & $(0.034)$ \\
\hline Sample sizes & \multicolumn{2}{|c|}{$18,463(8,297)$} & \multicolumn{2}{|c|}{$10,608(5,942)$} & & \\
\hline
\end{tabular}

Notes: The pre-reform period includes data from 2000 and 2003 PISA datasets whereas the post-reform period includes data from 2006 and 2009 PISA datasets. The table displays means and standard deviations shown in brackets. The asterisks indicate statistically significant differences between treatment and control states: **significant at $5 \%$ level; ***significant at $1 \%$ level. Standard errors in parenthesis are clustered at state level. The displayed sample sizes correspond to PISA datasets and are not weighted. The sample sizes in parenthesis refer to falling behind in primary and secondary school to which there is information only in 2003 and 2009 PISA waves. The relationship between the treatment and control states' sample varied across time because different states expanded their samples in different waves. For this reason, in all of our estimates we use the final student weights.

for doing so is that the Basque Country and Navarra have had greater fiscal and political autonomy since the mid 1970s and consequently their educational policy has differed from that of Spain as a whole. In particular, practically all 3-year-olds have been in childcare in the Basque Country and Navarra since the early 1990s. ${ }^{16}$ Data on children living in Ceuta and Melilla are only available in the PISA data from 2006 onwards.

Table 3 provides mean comparisons with respect to the outcomes of children living in high- versus low-intensity states before and after the reform. Regarding performance in the PISA tests, children in high-intensity states already outperform those in low-intensity states prior to the reform. After the reform, the performance gap across high- and low-intensity states further widens. This improvement is suggestive that the childcare reform might have increased children's cognitive development.

\section{Results}

\subsection{Underlying mechanisms}

When discussing the impact of expanding public childcare on children's development, it is important to bear in mind whether the expansion led to a crowding out of

\footnotetext{
${ }^{16}$ Potentially, one could use PISA 2000 and 2003 and analyze whether we find evidence of a differential effect on cognitive development between youths in Basque Country and Navarra and the rest of Spain. However, because of the greater fiscal and political autonomy in these two regions, it is likely that other policies may have occurred at the same time, confounding the effect of the universal childcare policy.
} 
alternative care modes. Therefore, we first discuss the changes in public and private childcare as well as maternal employment that arose after the introduction of the LOGSE. For the purpose of the latter, we re-estimate the results by Nollenberger and Rodríguez-Planas (2011). ${ }^{17}$

Panel A in Table 4 shows that children residing in high-intensity states were offered substantially more public childcare than those residing in low-intensity states: this differential increase amounted to 25.8 percentage points. ${ }^{18}$ Nonetheless, the reform did not lead to a crowding out of private childcare enrollment. While this result might come as a surprise, it is important to highlight that preschool for 3-year-olds was implemented within primary schools regardless of school ownership. Consequently, parents who wished to enroll their children in private school would now enroll their 3year-old in the private school as soon as preschool for that age group was offered (to guarantee a space thereafter). Panel A in Table 4 also shows that the effect of universal childcare on maternal employment is not only much smaller than the increase in the enrollment in childcare but also less precise. Despite not being statistically significantly different from zero, the economic interpretation of the estimate is that after the legislation was passed, mothers of 3-year-olds from fast-implementing states were 2.4 percentage points (or $6.7 \%$ ) more likely to work than their counterparts in slowimplementing states. ${ }^{19}$ While this finding might seem puzzling at first, it makes sense in the light of Spain being characterized by the male breadwinner model (as described in Section 2), especially since the reform was implemented during a period of low labor demand in a country well known for its rigid labor market.

Finally, it is important to note that the expansion in public childcare was unlikely to lead to a crowding out of informal care arrangements. Prior to the reform, $35.7 \%$ of mothers of 3-year-olds worked in treated states, while $32.5 \%$ of 3-year-olds were enrolled in formal care $(9.9 \%$ in public childcare and $22.6 \%$ in private childcare). Thus, most mothers of 3-year-olds who worked prior to the reform were likely to have their child already enrolled in either public or private childcare. The Spanish reform therefore mainly implied that mothers took their children to full-time childcare, even though they continued not to work.

Overall, our findings should be interpreted as the effects of an expansion in high-quality public childcare, which mainly led to a crowding out of family care, but not to a crowding out of private or informal care arrangements. This implies that our estimates mainly measure the effects of offering universal highquality childcare, as the reform under analysis did not imply a major income shock due to a shift from private to public childcare. Moreover, any potential income effect from an increase in maternal employment caused by the reform is modest at most.

\footnotetext{
${ }^{17}$ As explained at the end of Section 3, we adjust the identification strategy to be comparable to the baseline strategy of the current paper.

${ }^{18}$ We estimate the separate effect on the 1993/1994 and 1996/1997 cohorts and find similar coefficients (0.261 versus 0.256 ). As a consequence, we decided to pool both post-reform cohorts into one. Results when estimating our specification using the two cohorts separately are shown in Table 8 panel $\mathrm{C}$ and are discussed in Section 7.

${ }^{19}$ Prior to the reform, the average employment rate of mothers of 3-year-olds was $35.7 \%$ in fastimplementing states.
} 
Table 4 Main results

\begin{tabular}{|c|c|c|c|c|}
\hline & $\begin{array}{l}\text { ITT } \\
\text { (1) }\end{array}$ & $\begin{array}{l}\text { SE [ITT] } \\
\text { (2) }\end{array}$ & $\begin{array}{l}\text { Individual and } \\
\text { state-specific controls } \\
\text { (3) }\end{array}$ & $\begin{array}{l}\text { Individual controls } \\
\text { and state FE } \\
\text { (4) }\end{array}$ \\
\hline \multicolumn{5}{|c|}{ Panel A: Crowding out } \\
\hline \multicolumn{5}{|c|}{ Public childcare } \\
\hline \multirow[t]{3}{*}{ Treat $\times$ Post } & $0.258 * * *$ & {$[0.049]$} & & \\
\hline & $0.258 * * *$ & {$[0.052]$} & $\mathrm{X}$ & \\
\hline & $0.258 * * *$ & {$[0.060]$} & & $\mathrm{X}$ \\
\hline \multicolumn{5}{|l|}{ Private childcare } \\
\hline \multirow[t]{3}{*}{ Treat $\times$ Post } & 0.021 & {$[0.036]$} & & \\
\hline & 0.021 & {$[0.037]$} & $\mathrm{X}$ & \\
\hline & 0.021 & {$[0.043]$} & & $\mathrm{X}$ \\
\hline \multicolumn{5}{|c|}{ Maternal employment } \\
\hline \multirow[t]{3}{*}{ Treat $\times$ Post } & 0.037 & {$[0.051]$} & & \\
\hline & 0.024 & {$[0.058]$} & $\mathrm{X}$ & \\
\hline & 0.024 & {$[0.058]$} & & $\mathrm{X}$ \\
\hline \multicolumn{5}{|c|}{ Panel B: Children outcomes } \\
\hline \multicolumn{5}{|c|}{ Standardized reading scores } \\
\hline \multirow[t]{3}{*}{ Treated $\times$ Post } & $0.149 * *$ & {$[0.067]$} & & \\
\hline & $0.154 * *$ & {$[0.067]$} & $\mathrm{X}$ & \\
\hline & $0.154 * *$ & {$[0.067]$} & & $\mathrm{X}$ \\
\hline \multicolumn{5}{|c|}{ Standardized math scores } \\
\hline \multirow[t]{3}{*}{ Treated $\times$ Post } & 0.053 & {$[0.047]$} & & \\
\hline & 0.049 & {$[0.052]$} & $\mathrm{X}$ & \\
\hline & 0.049 & {$[0.052]$} & & $\mathrm{X}$ \\
\hline \multicolumn{5}{|c|}{ Falling behind a grade at primary school } \\
\hline \multirow[t]{3}{*}{ Treated $\times$ Post } & $-0.027^{*}$ & {$[0.014]$} & & \\
\hline & $-0.024 *$ & {$[0.013]$} & $\mathrm{X}$ & \\
\hline & $-0.025^{*}$ & {$[0.013]$} & & $\mathrm{X}$ \\
\hline \multicolumn{5}{|c|}{ Falling behind a grade at secondary school } \\
\hline \multirow[t]{3}{*}{ Treated $\times$ Post } & -0.032 & {$[0.036]$} & & \\
\hline & -0.032 & {$[0.035]$} & $\mathrm{X}$ & \\
\hline & -0.033 & {$[0.036]$} & & $\mathrm{X}$ \\
\hline
\end{tabular}

Notes: Standard errors (SE) clustered at state level are shown in brackets. Panel A first displays the results from estimating Eq. 1 using as the left hand side (LHS) variable the enrollment rate of 3-year-olds in public (private) schools. In this case we use annual data from the Spanish Ministry of Education, Culture and Sports. Sample size: 45 (15 states, 3 years). Panel A also displays the results from estimating Eq. 1 using as LHS variable the effects of LOGSE on maternal employment using Spanish LFS data. In this case, state-specific trends have been added in the specification. Sample size amounts to 105,748 mothers. Panel B presents the results from estimating Eq. 1 by OLS weighted using the final student weights. Sample sizes: for readings and math scores 40,340 and 38,091 students respectively; for the likelihood of falling a grade behind (only available in 2003 and 2009) 20,458 students. Columns (3) and (4) indicate whether the specification includes individual and pre-reform regional characteristics or individual characteristics and state fixed effects, respectively. The first two specifications of Panel A (public and private childcare) do not include individual controls as they were estimated at state level. The third specification (maternal employment) includes age, dummies indicating the mothers' level of education (high school (HS) dropout being the omitted category), immigration status, marital status, number of other children, quarterly dummies, and state-specific trends. Specifications in Panel B only include time-invariant characteristics: a gender dummy and immigration status. Pre-reform state characteristics included in all specifications in column (3) are those listed in Panel B in Table 2, with the exception of the initial level of childcare coverage when the LHS variable is the enrollment rate of 3-years-olds

*Significant at $10 \%$ level; **significant at $5 \%$ level; ***significant at $1 \%$ level 


\subsection{Children's cognitive long-term outcomes}

Panel B in Table 4 shows the impact of expanding public childcare on all children living in the high-intensity states - the so-called intention-to-treat effect-for four alternative outcome variables: test scores in reading and math, as well as the likelihood of falling behind one grade in primary and secondary school. All regressions are estimated using OLS and clustering standard errors at the state level, first not controlling for any further control variables and then controlling for pre-reform individual and state characteristics. Comparing the estimates with and without time-invariant individual and pre-reform regional controls in Panel B in Table 4 reveals no significant differences. We therefore focus our discussion on the latter specification.

Focusing first on the effects of the reform on children's standardized reading test scores at age 15, the effect of the expansion in public childcare for 3-year-olds is positive and statistically significant at any conventional significance level. The expansion of public childcare places leads to an increase in reading test scores by $0.15 \mathrm{SD}$. We cannot find a significant effect of the reform on children's math performance. Thus, our results are in line with the expectations that the activities undertaken in public childcare stimulate children's social and emotional competencies and thus their language and reading skills but not necessarily their math skills.

How do these effects compare to the established evidence? The existing studies evaluating the impact of universal childcare provision find effects of similar direction and size, despite being measured at an earlier age. In the case of an Argentinean reform, Berlinski et al. (2009) find a substantial improvement of cognitive skills (by 0.23 SD) among children in the third grade. Analyzing the consequences of the introduction of universal childcare in Georgia (USA) on the reading and math skills among children in fourth grade, Fitzpatrick (2008) finds slightly lower effects and only for the population of disadvantaged children, defined as those living in rural areas. More specifically, she finds significant gains, ranging between 0.07 and $0.12 \mathrm{SD}$ for reading scores, and between 0.06 and 0.09 SD for math scores.

Moving to the effects of the reform on the likelihood of falling behind a grade, we also find beneficial effects of the reform. More specifically, we observe that the reform reduced the incidence of falling behind a grade by 2.4 percentage points in primary school. Given the initial likelihood of falling behind a grade among children in the treated states of $5 \%$ in primary school, the effect of the reform represents a substantial decrease in the incidence of retention (almost $50 \%$ ). While the estimations also indicate a reduction of falling behind in secondary school, the estimated coefficient is not significant at any conventional significance level. In other words, while initial gains in cognitive skills might be strong enough to help children master the requirements to pass a grade during primary school, they might not necessarily be sufficient to make a difference in secondary school.

The two existing studies considering the consequences of universal childcare provision on this outcome are US studies by Fitzpatrick (2008) and Cascio (2009). Our results are similar to those found by Fitzpatrick (2008) for disadvantaged children. In fact, analyzing universal pre-kindergarten in Georgia, she finds that the probability of being on-grade for their age (fourth graders and thus in primary school) increases by 7 percentage points (about $10 \%$ ) among black children. By contrast, analyzing the longterm effects of public childcare provision, Cascio (2009) did not find any significant improvements in grade retention. One possible reason behind the differences between 
our results and those of Cascio (2009) is that she analyzes the effects of introducing low-intensity kindergarten for 5-year-olds, while we analyze the effects of high-quality full-time childcare for 3-year-olds.

\section{Sensitivity analysis}

In this section, we address several potential sources of bias. In particular, we discuss issues such as selective migration and common trend assumption, as well as adding further specification checks.

Selective migration: One potential source of bias might be selective migration, whereby families might have moved from slow-implementing states to fast-implementing states. Since PISA only provides information on the state of residence at age 15 (but not at age 3), we rely on the LFS (for 2000, 2003, 2006 and 2009) to assess the concern of selective migration. We first assess the likelihood of living at age 15 in a state different from the state of birth. However, this probability is small (4.0\% in 2000, $4.6 \%$ in $2003,5.2 \%$ in 2006 , and $4.9 \%$ in 2009). Second, we estimate the likelihood of having migrated from a low- to a high-implementing state (and vice versa). The results do not indicate an increased migration into high-implementing states (shown in Table 5, Panel A). Thus, selective migration should not be a major threat for the internal validity of the study. ${ }^{20}$

Common trend assumption: The strongest assumption underlying any DiD estimation is the absence of any differential time trend in high- and low-implementing states. Besides inspecting pre-existing trends, the most commonly used test to shed some light on this assumption is to estimate the effect of a placebo reform, pretending that the reform took place at an earlier moment in time. Given the time horizon of PISA data, we can only pursue a placebo test assuming that the reform took place in the late 1980s and thus affected the cohort born in 1987 (the PISA cohort 2003) but not the cohort born in 1984 (the PISA cohort 2000). Re-estimating Eq. 1 but using only PISA 2000 and 2003 data and treating the PISA 2003 cohort as the post-reform cohort do not reveal any significant impact of the imaginary policy change on children's reading and math test scores (see Panel B in Table 5). Note that we do not lose precision in this specification, but instead the size of the coefficients is cut in half and are no longer significant.

In addition, we estimate a specification where we use a more homogenous sample of states and exclude the poorest and richest states from our sample. In doing so, we want to address the fact that Spanish regions strongly differ in their economic development and thus might potentially follow differential trends. The results are fairly robust to this sample restriction. Three of the four coefficients increase in size in this specification, although only the effect on reading is statistically significant (see Table 6, column 2). Finally, we estimate a specification in which we interact the Post dummy with all prereform regional characteristics shown in Table 2 (Duflo 2001). In doing so, we check whether regional pre-reform characteristics are correlated with the development of children's cognitive skills over time. The results shown in column 3 of Table 6 are

\footnotetext{
${ }^{20}$ In addition, the migration flow by skill level is similar to the ones presented in the table and does not indicate any migration flows that would threaten our identification strategy.
} 
Table 5 Robustness checks

\begin{tabular}{llll}
\hline ITT & SE [ITT] & $\begin{array}{l}\text { Individual } \\
\text { and state- } \\
\text { specific } \\
\text { controls }\end{array}$ & $\begin{array}{l}\text { Individual } \\
\text { controls } \\
\text { and state FE }\end{array}$ \\
\hline
\end{tabular}

Panel A Effect on probability of having migrated across states by age 16 using LFS

A.1 From control to treatment states

Treated $\times$ Post

$\begin{array}{ll}-0.006 & {[0.009]} \\ -0.006 & {[0.009]} \\ -0.006 & {[0.009]}\end{array}$

$\mathrm{X}$

$\mathrm{X}$

A.2 From treatment to control states

Treated $\times$ Post

$\begin{array}{ll}0.009 & {[0.006]} \\ 0.009 & {[0.006]} \\ 0.009 & {[0.006]}\end{array}$

X

[0.006]

X

Panel B Placebo test: pre-reform data

Standardized reading scores

Treated $\times$ Cohort 90

0.082

[0.061]

0.085

0.086

[0.060]

X

Standardized math scores

Treated $\times$ Cohort 90

$\begin{array}{ll}0.000 & {[0.060]} \\ 0.025 & {[0.063]} \\ 0.025 & {[0.062]}\end{array}$

$\mathrm{X}$

[0.062]

$\mathrm{X}$

Notes: The table displays the results from estimating Eq. 1 using different outcomes as LHS variable. In each case, we present the raw estimate and also one that includes individual controls (invariant characteristics) and either the pre-regional characteristics listed in the Panel B of Table 2 or state fixed effects. In Panel A.1, the LHS variable is a dummy equal to one if the individual has migrated from a control to a treatment state (and vice versa in Panel A.2). We use all quarters of 2000, 2003, 2006, and 2009 LFS and restrict the sample to natives. The total sample size is of 27,602 observations. In Panel B, we estimate Eq. 1 using only 2000 and 2003 PISA datasets, assuming that the reform took place in between 1988 and 1990. Sample size, 11,400 and 9,151 students for readings and math scores, respectively. Standard errors clustered at state level are shown in brackets.

robust and provide supportive evidence for the underlying assumption of common time trends (at least in terms of observables).

Further robustness checks: Finally, we carry out the following additional sensitivity checks. First, some states (Andalucía, Canary Island, Catalonia, Valencia, and Galicia) traditionally had more control over their education policy. Since this may affect our results, we have re-estimated a specification, adding a dummy for these five states and interacting it with the post-reform dummy (shown in Table 6, column 4). Second, as in Havnes and Mogstad (2011), we experiment with a different definition of the treatment and the control groups, whereby high-implementing states are defined as those with growth in public enrollment above the 67 th percentile, and low-implementing states are those with growth in public enrollment below the 33th percentile (shown in Table 6, column 5). In addition, we use alternative cut-offs for the definition of treatment and control states and include the state with the lowest increase of public childcare among the high-implementing states into the 


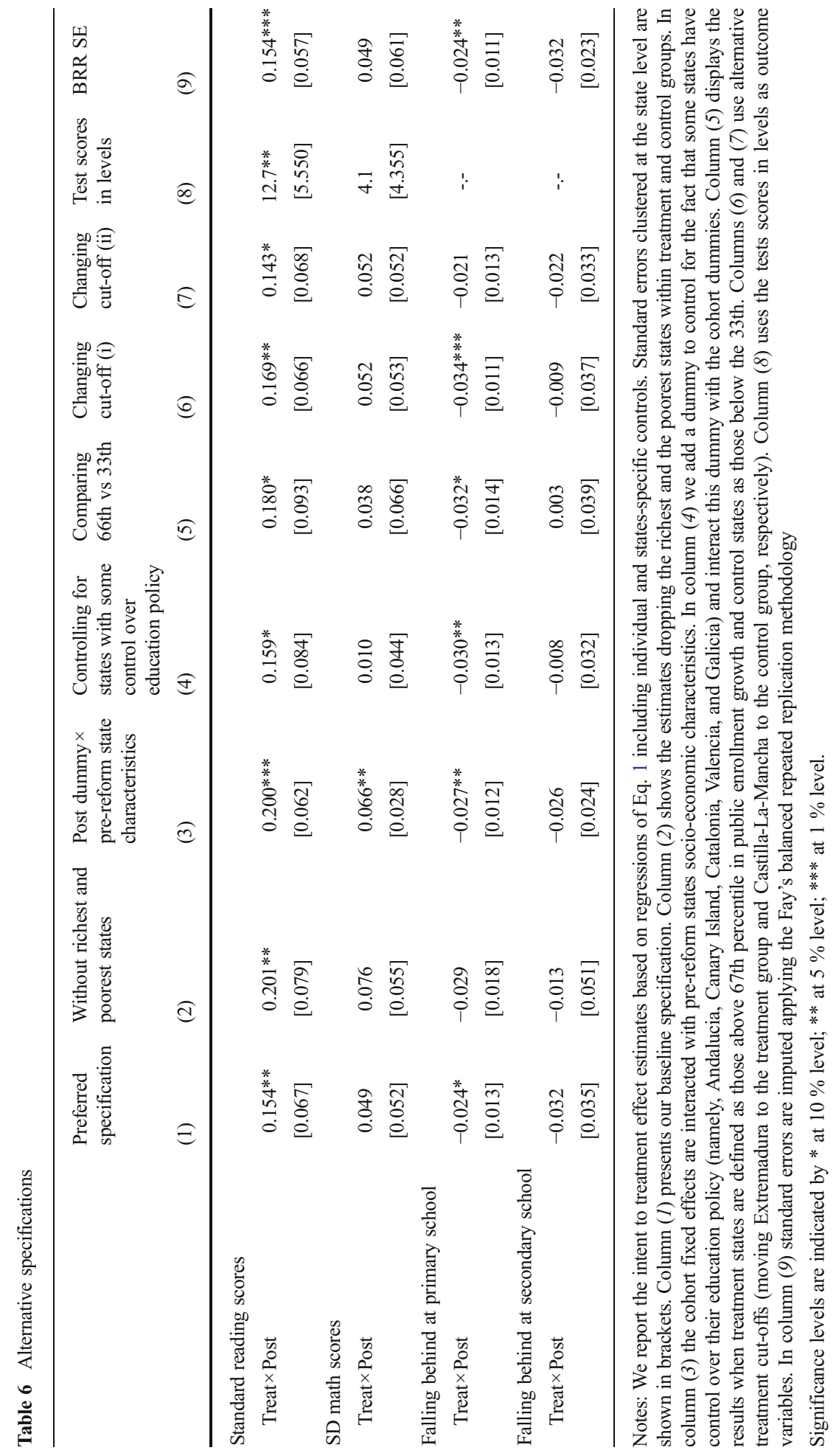


low-implementing states in one alternative specification, as well as the state with the highest increase of public childcare among the low-implementing states into the highimplementing states in another alternative specification (shown in Table 6, columns 6 and 7, respectively). In addition, we repeat our estimations using the levels of the outcome variables rather than the standardized test scores (shown in column 8). Finally, column 9 shows a specification that takes into account the double stratification nature of the sampling design employed by PISA, whereby we run our regression applying the Fay's BRR methodology. Notice that this method implies clustering at the school level. Overall, the results regarding reading scores are robust to all of these sensitivity checks, while the results regarding falling behind a grade in primary school are robust to six out of eight robustness checks (see Table 6). ${ }^{21}$

Alternative identification: Estimates from Eq. 2 are shown in Table 7. Offering one more slot per hundred children leads on average to a statistically significant improvement in children's reading test scores $(0.01 \mathrm{SD})$ and a statistically significant reduction in the likelihood of falling behind a grade while in primary school of 0.2 percentage points. Given the average increase in public enrollment by 25.8 percentage points after the introduction of LOGSE, this implies an improvement of $0.26 \mathrm{SD}$ in reading test scores and a reduction of about 5.2 percentage points in the likelihood of falling behind a grade in primary school. Analogous to the baseline specification, there does not seem to be a statistically significant effect on math test scores and falling behind a grade during high school. ${ }^{22}$

\section{Heterogeneity analysis}

Table 8 displays estimates by children's gender, children's birth cohort, and parents' educational level. Such analysis might reveal policy relevant effect heterogeneity.

Gender: Estimates from Panel A in Table 8 reveal that universal preschool provision had large, positive, and significant effects on girls' cognitive development. We observe a significant improvement in reading skills by $0.19 \mathrm{SD}$, while math test scores also increase by $0.11 \mathrm{SD}$, yet they are not significant at any conventional level. We also find positive and significant effects (at the $90 \%$ level) on grade retention among girls, whereby those in the high-intensity states are 2.4 percentage points $(50 \%)$ less likely to

\footnotetext{
${ }^{21}$ Appendix Table A.2 explores additionally the sensitivity of our results to sequentially adding other (potentially endogenous) regional characteristics, individual characteristics, such as family characteristics (parents' level of education and home possessions), type of school, and population density of the area of residence. While the effect on reading is robust across all specifications, the estimate on falling behind a grade becomes practically zero when regional characteristics are included. In this specification (column 2), the reform has a significant and beneficial effect on grade retention during secondary school. Yet, it is important to keep in mind that these additional control variables are likely to be affected by the reform and thus the estimated coefficients represent only net (off potential channels) effects of the reform on children's cognitive long-run development.

${ }^{22}$ While additional analysis adding a second-order polynomial of the number of available seats does not indicate any nonlinear impact of public childcare slots on children's long-run cognitive development, using a step function instead does indicate that the effect is the effect of adding slots when the supply is still low (e.g., below the median and even in the lower tercile) is stronger than when the supply is rising. This evidence goes in line with the subgroup analysis by cohort which indicates stronger effects for the cohort 1990 when the supply of slots was still low than for the cohort 1993 when the supply of slots had already risen.
} 
Table 7 Alternative identification strategy

ITT

Se [ITT]

Standardized reading scores

Seats

$0.010 * *$

[0.003]

Standardized math scores

Seats

0.002

Falling behind at primary school

Seats

$-0.002 * * *$

$[0.000]$

Falling behind at secondary school

Seats

0.001

$[0.002]$

Notes: The table displays the results from estimating the Eq. 2-see main text for details. Standard errors clustered at state level are shown in brackets. The specification includes state fixed effects and time-invariant individual characteristics (a gender dummy and immigration status). Sample sizes: for readings and math scores 40,340 and 38,091 students, respectively; for the likelihood of falling a grade behind (only available in 2003 and 2009) 20,458 students

** Significant at $5 \%$ level; *** significant at $1 \%$ level.

fall behind a grade during primary school and 4.5 percentage points $(23.7 \%)$ during secondary school (although only the former coefficient is significant at the $90 \%$ significance level). For boys, the point estimate for reading skills is 0.12 and for falling behind a grade during primary school is 2.4 percentage points. However, the standard errors render the boys' results uninformative.

Other authors have also found that public childcare improves girls' cognitive skills. For instance, Gathmann and Saß (2012) find that attending public childcare improves girls' early development of socio-motor skills. In a study by Havnes and Mogstad (2011), improved labor market outcomes due to an expansion of public childcare are also only present among women (although the authors find that both men and women benefit similarly in terms of educational outcomes, such as secondary school completion or college attendance).

Parental education: Panel B in Table 8 presents results by parents' educational level. Gains in cognitive performance due to universal childcare are more pronounced among children of low-skilled parents, defined as children for whom neither parent has a secondary school degree. To be more precise, we observe a significant improvement in reading skills among low-skilled families by $0.17 \mathrm{SD}$. In addition, we also find positive effects on grade retention during primary school, whereby children in the high-intensity states are 4 percentage points $(59.7 \%$ ) less likely to fall behind a grade in primary school. However, the effect is not significant at any conventional level.

These results are again consistent with those found by others. For instance, Fitzpatrick (2008) only finds substantial effects of the introduction of universal prekindergarten on disadvantaged children residing in small towns and rural areas. Similarly, Havnes and Mogstad (2011) show that universal childcare provision has positive long-run effects on income equality.

Cohort: Finally, we test whether the effect of expanding childcare was consistent over time. For this purpose, we split our post-reform cohort into the birth cohort 1990 (PISA 
Table 8 Heterogeneous effects

\begin{tabular}{|c|c|c|c|c|}
\hline Panel A: By gender & \multicolumn{2}{|l|}{ Boys } & \multicolumn{2}{|l|}{ Girls } \\
\hline \multicolumn{5}{|c|}{ Standardized reading scores } \\
\hline Treated $\times$ Post & 0.119 & {$[0.074]$} & $0.191 * *$ & {$[0.075]$} \\
\hline \multicolumn{5}{|c|}{ Standardized math scores } \\
\hline Treated $\times$ Post & -0.011 & {$[0.050]$} & 0.107 & {$[0.067]$} \\
\hline \multicolumn{5}{|c|}{ Falling behind a grade at primary school } \\
\hline Treated $\times$ Post & -0.024 & [0.019] & $-0.024 *$ & {$[0.013]$} \\
\hline \multicolumn{5}{|c|}{ Falling behind a grade at secondary school } \\
\hline Treated $\times$ Post & -0.019 & {$[0.045]$} & -0.045 & {$[0.030]$} \\
\hline Panel B: By education & \multicolumn{2}{|c|}{$\begin{array}{l}\text { Neither of the parents have } \\
\text { a secondary school } \\
\text { degree }\end{array}$} & \multicolumn{2}{|c|}{$\begin{array}{l}\text { At least one of the parents have } \\
\text { a secondary school degree }\end{array}$} \\
\hline \multicolumn{5}{|c|}{ Standardized reading scores } \\
\hline Treated $\times$ Post & $0.168 * *$ & {$[0.064]$} & 0.113 & {$[0.066]$} \\
\hline \multicolumn{5}{|c|}{ Standardized math scores } \\
\hline Treated $\times$ Post & 0.041 & {$[0.074]$} & 0.025 & {$[0.051]$} \\
\hline \multicolumn{5}{|c|}{ Falling behind at primary school } \\
\hline Treated $\times$ Post & -0.040 & [0.029] & -0.007 & {$[0.009]$} \\
\hline \multicolumn{5}{|c|}{ Falling behind at secondary school } \\
\hline Treated $\times$ Post & -0.037 & {$[0.060]$} & -0.019 & {$[0.032]$} \\
\hline Panel C: By cohort & \multicolumn{2}{|c|}{ Cohort 1990} & \multicolumn{2}{|c|}{ Cohort 1993} \\
\hline \multicolumn{5}{|c|}{ Standardized reading scores } \\
\hline Treated $\times$ Post & $0.172 * *$ & {$[0.074]$} & 0.137 & {$[0.080]$} \\
\hline \multicolumn{5}{|c|}{ Standardized math scores } \\
\hline Treated $\times$ Post & 0.082 & {$[0.058]$} & 0.018 & {$[0.069]$} \\
\hline
\end{tabular}

Notes: Panel A and Panel B display the results from estimating Eq. 1 including controls for individual and specific regional characteristics. Standard errors clustered at state level are shown in brackets. In Panel A, sample sizes: for boys, reading scores 20,094, math scores 18,980, grade repetition 11,208; for girls: reading scores 20,246, math scores 19,111, grade repetition 11,231. In Panel B, sample sizes: for those with parents of low education, reading scores 10,984, math scores 10,329, grade repetition 5,743; for those with at least one parent of high education: reading scores 29,356, math scores 27,762, grade repetition 16,696. In Panel C, sample sizes: for cohort 1990: reading scores 24,271, math scores 22,022; for cohort 1993: reading scores 27,469, math scores 25,220

*Significant at $10 \%$ level; **significant at $5 \%$ level.

cohort 2006) and the birth cohort 1993 (PISA cohort 2009). However, we can only do so for reading and math test scores, given that information on falling behind was only asked in PISA 2009. As we can see in Panel C, Table 8 three of the four coefficients are quite large, although standard errors render two of these three results uninformative. Only the effect on reading for the 1990 cohort is statistically significant.

It is important to point out that while the expansion in public childcare between high- and low-intensity states was equally strong for both birth cohorts (26.1 and 25.6 percentage points), enrollment rates among children of the 1990 cohort were still lower than among those of the 1993 cohort (44.0 versus $57.1 \%$ ). Thus, our findings are again 
in line with the previous findings indicating differential effects of public childcare depending on the level of supply (Felfe and Lalive 2012).

To conclude, it remains to say that although the results seem to be driven by the earlier cohort, girls and children from a lower socio-economic background, differences between the respective subgroups are not statistically significant.

\section{Conclusions}

There is fervent current political debate concerning the extent to which the Government must provide sufficient, affordable childcare. For instance, on June 6, 2012 the German Government approved a bill to give parents of toddlers an allowance for keeping their children out of state-run day care, instead of investing in the expansion of childcare centers (New York Times 2012). At the same time, in countries hard hit by the Great Recession, such as Spain, many governments are rolling back subsidized childcare (New York Times 2012). A major concern among opponents of public childcare is its high costs for a nonmandatory service for which the short- and long-term gains on the children's development relative to other forms of early childcare (such as parental, informal, or private care) remain uncertain. Indeed, there is still limited consensus in the literature about the effect of childcare on child development, partly as the effects of universalizing childcare depend on the quality of both public childcare and the counterfactual care mode.

This paper contributes to closing this gap in the literature by providing quasi-experimental evidence of the impact of shifting hours of care provided by mothers to hours of care provided by high-quality public preschools. We find that high-quality public childcare not only neutralizes potentially negative effects of maternal employment but even has positive effects on children's cognitive development, at least among children with less educated parents and for girls. Hence, these early childhood investments might well pay off themselves in the long run.

One crucial feature of the childcare expansion under study, however, is the guarantee of maintaining high-quality care. In the absence of quality regulations, a rapid expansion of universal care might well have negative consequences on children's development. Hence, sending children to public childcare might indeed be one way to "buy mommy's love", albeit only if the quality of care provided in the childcare centers meets that provided by the mother.

\footnotetext{
Acknowledgments We would like to thank the editor, Erdal Tekin, and three anonymous referees for helpful comments that greatly improved the paper. The authors are also grateful to Manuel Bagues, Paul Devereux, Susan Dinarsky, Maria Fitzpatrick, Libertad González, Lídia Farré, Michael Lechner, Oskar Nordström Skans, Björn Öckert, Xavi Ramos, Antonio Cabrales, Ismael Sanz Labrador, Uta Schönberg, Anna Sjögren, Anna Vignoles, Conny Wunsch, Natalia Zinovyeva, as well as participants from the V INSIDE-MOVE, NORFACE, and CReAM Workshop on Migration and Labor Economics, the III Workshop on Economics of Education "Improving Quality in Education," the CESifo Area Conference on the Economics of Education, the RES Annual Meeting, the SOLE Annual Meeting, the ESPE Annual Meeting the EALE Annual Meeting as well as seminars at DIW, IFAU, University College Dublin, Ludwigs-Maximilians Universität, and University of St Gallen. The authors also would like to thank the Spanish Instituto Nacional de Evaluación Educativa (INEE) del Ministerio de Educación, Cultura y Deporte for facilitating access to the geo-codes for PISA 2000 and Brindusa Anghel from FEDEA for her support with the Spanish Labor Force Survey.
} 


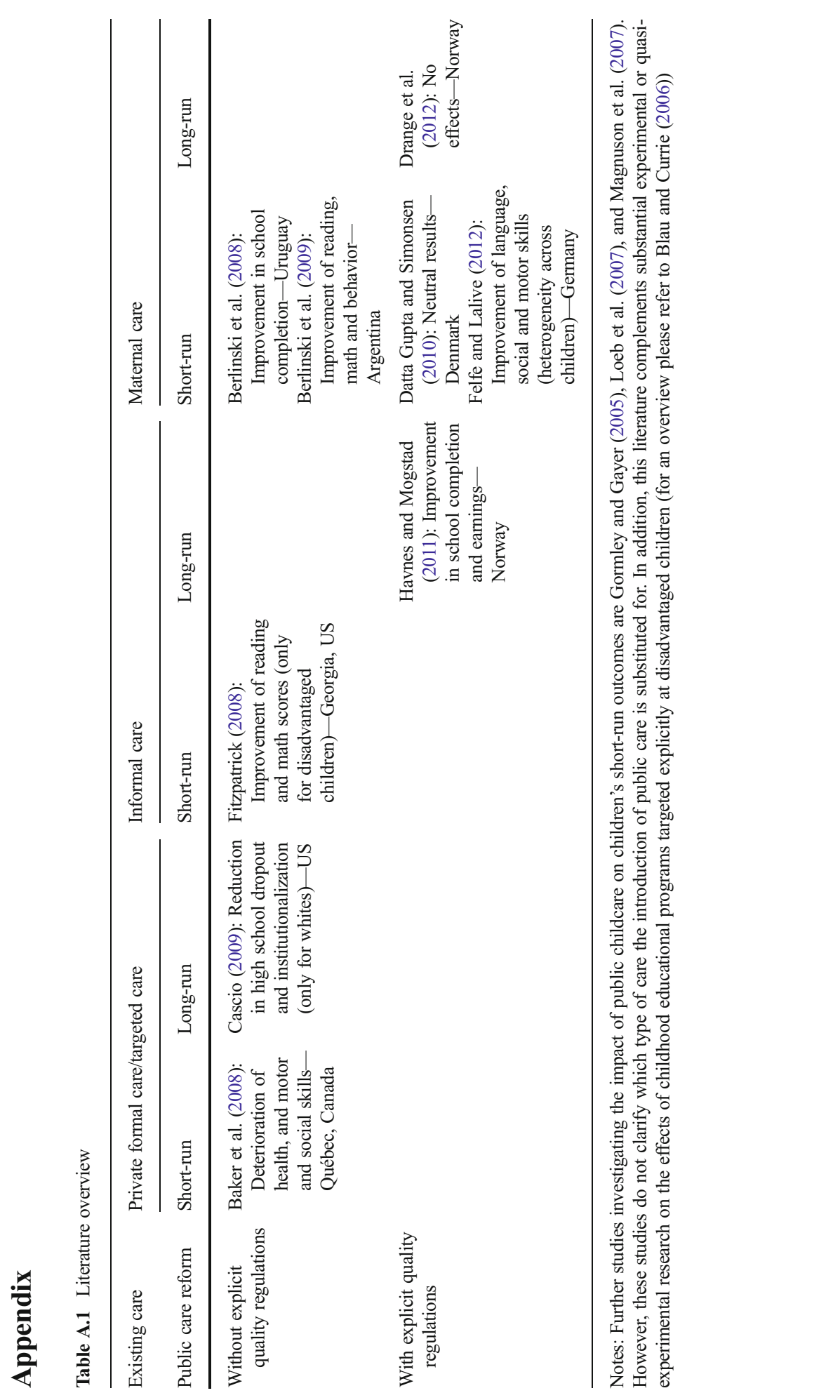


Table A.2 Sensitivity analysis of covariates included

\begin{tabular}{|c|c|c|c|c|c|}
\hline & $\begin{array}{l}\text { Unconditional } \\
\text { (1) }\end{array}$ & $\begin{array}{l}+ \text { Regional } \\
\text { characteristics } \\
\text { (2) }\end{array}$ & $\begin{array}{l}\text { + Individual } \\
\text { characteristics } \\
\text { (3) }\end{array}$ & $\begin{array}{l}+ \text { Family } \\
\text { characteristics } \\
\text { (4) }\end{array}$ & $\begin{array}{l}+ \text { Type } \\
\text { of school } \\
\text { (5) }\end{array}$ \\
\hline \multicolumn{6}{|c|}{ Standardized reading score } \\
\hline \multirow[t]{2}{*}{ Treat $\times$ Post } & $0.149 * *$ & $0.122 * *$ & $0.154^{* *}$ & $0.118^{*}$ & $0.119^{*}$ \\
\hline & {$[0.067]$} & {$[0.047]$} & {$[0.067]$} & {$[0.065]$} & {$[0.066]$} \\
\hline \multicolumn{6}{|c|}{ Standardized math scores } \\
\hline \multirow[t]{2}{*}{ Treat $\times$ Post } & 0.053 & 0.056 & 0.049 & 0.017 & 0.025 \\
\hline & {$[0.047]$} & {$[0.065]$} & {$[0.052]$} & {$[0.036]$} & {$[0.038]$} \\
\hline \multicolumn{6}{|c|}{ Falling behind a grade at primary school } \\
\hline \multirow[t]{2}{*}{ Treat $\times$ Post } & $-0.027 *$ & -0.007 & $-0.024^{*}$ & $-0.023^{*}$ & $-0.029 * *$ \\
\hline & {$[0.014]$} & {$[0.016]$} & {$[0.013]$} & {$[0.012]$} & {$[0.013]$} \\
\hline \multicolumn{6}{|c|}{ Falling behind a grade at secondary school } \\
\hline \multirow[t]{2}{*}{ Treat $\times$ Post } & -0.032 & $-0.068^{* *}$ & -0.032 & -0.026 & -0.034 \\
\hline & {$[0.036]$} & {$[0.031]$} & {$[0.035]$} & {$[0.034]$} & {$[0.036]$} \\
\hline
\end{tabular}

Notes: Above results are estimated using Eq. 1 and including as additional control variables (2) the GDP per capita, the proportion of HS dropouts and the average years of education by state for the years when the cohorts assessed in each PISA wave were 3 years old, that is, 1987, 1990, 1993, and 1996 - these three variables are those for which we could not reject the tests of parallel trends between the treated and comparison states (see Appendix Table A.3); (3) individual characteristics: male, immigrants; (4) family characteristics: home possession score (an index derived from students' responses to the following items: Do you have: a desk for study, a room of your own, a computer, internet, classic literature, books, works of art, dishwasher, among others), mother's and father's education; (5) type of school: public-omitted, private. Standard errors clustered at state level are shown in brackets *Significant at $10 \%$ level; **significant at $5 \%$ level

Table A.3 Difference-in-difference estimates for regional features

\begin{tabular}{lc}
\hline & Baseline specification \\
\hline Unemployment rate & 0.011 \\
GDP per capita & {$[0.011]$} \\
& $509.552^{*}$ \\
Women employment rate & {$[275.751]$} \\
& -0.027 \\
College graduate & {$[0.017]$} \\
& 0.002 \\
HS dropouts & {$[0.005]$} \\
& $0.022^{* * *}$ \\
Years of education & {$[0.007]$} \\
Population $0-6$ & $-0.127^{* * *}$ \\
Immigrants & {$[0.036]$} \\
& -4.402 \\
& {$[20.313]$} \\
\hline
\end{tabular}

Notes: Standard errors clustered at state level are shown in brackets. Results from estimating Eq. 1 using as the LHS variable those in Fig. 3 and controlling for state and year fixed effects. Sample size, 300

HS high school

*Significant at $10 \%$ level; *** significant at $1 \%$ level 


\section{References}

Adserà A (2004) Changing fertility rates in developed countries. The impact of labor market institutions. J Popul Econ 17(1):17-43

Amuedo-Dorantes C, de la Rica S (2009) The timing of work and work-family conflicts in Spain: who has a split work schedule and why? IZA discussion paper 4542

Baker M, Milligan K (2011) Maternity leave and children's cognitive and behavioral development. NBER working paper 17105 .

Baker M, Gruber J, Milligan K (2008) Universal child care, maternal labor supply, and family well-being. J Polit Econ 116(4):709-745

Bauchmüller R, Gørtz M, Würtz-Rasmussen A (2014) Long-run benefits from universal high-quality preschooling. Early Child Res Q 29(4):457-470.

Berlinski S, Galiani S (2007) The effect of a large expansion in pre-primary school facilities on preschool attendance and maternal employment. Labour Econ 14(3):665-680

Berlinski S, Galiani S, Manacorda M (2008) Giving children a better start: preschool attendance and schoolage profiles. J Public Econ 92(5):1416-1440

Berlinski S, Galiani S, Gertler P (2009) The effect of pre-primary education on primary school performance. J Public Econ 93(1-2):219-234

Bettinger E, Haegeland T, Rege M (2013) Home with mom: the effects of stay-at-home parents on children's long-run educational outcomes. CESifo working papers 4274

Bettio F, Villa P (1998) A Mediterranean perspective on the breakdown of the relationship between participation and fertility. Cambridge J Econ 22(2):137-171

Black S, Devereux P, Loken K, Salvanes K (2012) Care or cash? The effect of child care subsidies on student performance. NBER working paper 18086

Blau D, Currie J (2006) Preschool, day care, and after school care: who's minding the kids? In: Hanushek E, Welsh F (eds) Handbook of economics of education vol 2. Amsterdam, North Holland Press, pp. 1163-278

Carneiro P, Løken K, Salvanes K (2011) A flying start? Maternity leave benefits and long run outcomes of children. IZA discussion paper 5793

Cascio E (2009) Do investments in universal early education pay off? Long-term effects of introducing into public schools. NBER working paper 14951

Datta Gupta N, Simonsen M (2010) Non-cognitive child outcomes and universal high quality child care. J Public Econ 94(1-2):30-42

Drange N, Havnes T, Sandsør A (2012) Kindergarten for all: long run effects of a universal intervention. Stat Norway DP 695

Duflo E (2001) Schooling and labor market consequences of school construction in Indonesia: evidence from an unusual policy experiment. Am Econ Rev 91(4):795-813

Dustmann C, Schöenberg U (2012) Expansions in maternity leave coverage on children long-term outcomes. Am Econ J Appl Econ 4(3):190-224

Economist. Does subsidized preschool pay-off? 13 February 2013

Economist, Fighting over the kinder. 17 August 2013

El País, La LOGSE, 15 años después (by Elena Martín Ortega). 3 October 2005

Felfe C, Lalive R (2012) Early child care and child development: for whom it works and why. IZA Discussion Papers 7100 .

Felgueroso F, Gutiérrez M, Jimenez S (2014) Why school dropout remained so high in the last two decades? The role of the educational law (LOGSE). IZA J Labor Policy 3:9, 9 May 2014

Fernández-Kranz D, Rodríguez-Planas N (2011) The part-time penalty in a segmented labor market. Labour Econ 18(5):591-606

Fitzpatrick M (2008) Starting school at four: the effect of universal pre-kindergarten on children's academic achievement. BE J Econ Anal Poli 8(1):1-38

Gathmann C, Saß B (2012) Taxing childcare: effects on family labor supply and children. IZA discussion paper 6640

Gormley W Jr, Gayer T (2005) Promoting school readiness in Oklahoma. An evaluation of Tulsa's pre-k program. J Hum Resour 3:533-558

Gutierrez-Domenech M (2005) Employment transitions after motherhood in Spain. Labour 19:123-148

Havnes T, Mogstad M (2011) No child left behind: subsidized child care and children's long-run outcomes. Am Econ J Econ Policy 3:97-129

Lenneberg, E (1964) The capacity of language acquisition. In: J Fodor and J Katz (eds) The structure of language. Englewood Cliffs, NJ: Prentice Hall, pp 579-603 
Liu Q, Oskar S (2010) The duration of paid parental leave and children's scholastic performance. BE J Econ Anal Poli 10(1):1935-1682

Loeb S, Bridges M, Bassok D, Fuller B, Rumberger R (2007) How much is too much? The influence of preschool centers on children's social and cognitive development. Econ Educ Rev 26:52-66

LOGSE, Ley Orgánica 1, 1990 de Ordenación General del Sistema Educativo, 03.10.2013, BOE No. 238, 28927-28942

Magnuson K, Ruhm C, Waldfogel J (2007) Does prekindergarten improve school preparation and performance? Econ Educ Rev 26(1):33-51

Montessori M (1963) The secret of childhood. Ballentine Books, New York

New York Times. German Lawmakers Spar Over Child Care Subsidy, by Melissa Eddy. 6 Jun 2012

Nollenberger N, Rodríguez-Planas, N (2011) Child care, maternal employment and persistence: a natural experiment from Spain. IZA discussion paper 5888

OECD (2006). PISA 2006 science competencies for tomorrow's world

Rasmussen A (2010) Increasing the length of parents' birth-related leave: the effect on children's long-term educational outcomes. Labour Econ 17(1):91-100 